\title{
A small molecule induces integrin $\beta 4$ nuclear translocation and apoptosis selectively in cancer cells with high expression of integrin $\beta 4$
}

\author{
ShuYan Liư ${ }^{1}$, Di Ge ${ }^{2,3}$, LiNa Chen ${ }^{1}$, Jing Zhao ${ }^{1}$, Le Su${ }^{1}$, ShangLi Zhang ${ }^{1}$, JunYing Miao ${ }^{1,4}$, \\ BaoXiang Zhao ${ }^{3}$ \\ ${ }^{1}$ Shandong Provincial Key Laboratory of Animal Cells and Developmental Biology, School of Life Science, Shandong University, \\ Jinan 250100, China \\ ${ }^{2}$ School of Biological Science and Technology, University of Jinan, Jinan 250022, China \\ ${ }^{3}$ Institute of Organic Chemistry, School of Chemistry and Chemical Engineering, Shandong University, Jinan 250100, China \\ ${ }^{4}$ The Key Laboratory of Cardiovascular Remodeling and Function Research, Chinese Ministry of Education and Chinese \\ Ministry of Health, Qilu Hospital, Shandong University, Jinan 250012, China \\ Correspondence to: BaoXiang Zhao, e-mail: bxzhao@sdu.edu.cn \\ JunYing Miao, e-mail: miaojy@sdu.edu.cn
}

Keywords: chemical small molecules, integrin $\beta 4$ high expression cancer, ANXA7, ATF3, apoptosis

Received: September 14, 2015

Accepted: February 05, 2016

Published: February 23, 2016

\section{ABSTRACT}

Increased integrin $\beta 4$ (ITGB4) level is accompanied by malignant progression of multiple carcinomas. However, selective therapeutic strategies against cancer cells expressing a high level of ITGB4 have not been reported. Here, for the first time, we report that a chiral small molecule, SEC, selectively promotes apoptosis in cancer cells expressing a high level of ITGB4 by inducing ITGB4 nuclear translocation. Nuclear ITGB4 can bind to the ATF3 promoter region and activate the expression of ATF3, then upregulate the downstream pro-apoptosis genes. Furthermore, SEC promoted the binding of annexin A7 (ANXA7) to ITGB4 and increased ANXA7 GTPase activity. Activated ANXA7 promoted ITGB4 nuclear translocation by triggering ITGB4 phosphorylation at Y1494. SEC also inhibited the growth of xenograft tumors in the avian embryo model. We identified a small molecule, SEC, with selective pro-apoptosis effects on cancer cells with high expression of ITGB4, both in vitro and in vivo, by triggering the binding of ITGB4 and ANXA7, ITGB4 nuclear trafficking, and pro-apoptosis gene expression.

\section{INTRODUCTION}

Integrin $\beta 4$ (ITGB4) is the structural component of hemidesmosomes (HDs) that maintains epithelial architecture and also acts as a signaling adaptor driving tumor cell proliferation and movement $[1,2]$. The two contrasting roles of ITGB4 in stable adhesion and pro-invasion are significantly correlated to its subcellular distribution. In normal epithelial cells, ITGB4 is incorporated in HDs, which contributes to the anchor of epothelial cells to the basal membrane. In carcinoma cells, ITGB4 redistributes from HDs to the leading edges of cells enriched at lamellipodia and filopodia and promotes tumor migration and invasion [3,4]. Palmitoylation of ITGB4 cysteine residues results in ITGB4 mobilizing to lipid rafts. Lipid raft localization of ITGB4 is necessary for its binding to palmitoylated Src family kinase (SFK) and promoting EGF-dependent proliferation [5]. Hypoxiainduced recruitment of ITGB4 to rafts and the following internalization into multivesicles resulted in a shift from adhesion to metastasis [6].

This behavior of promoting tumor progression explains the upregulation of ITGB4 in multiple cancer cells and suggests that ITGB4 redistribution affords cells with advantages for proliferation and invasion. However, the growth-inhibitory effect of ITGB4 in carcinoma cells is not clear. The relevance of integrins in cancer progression has prompted the production of integrin $\beta 1$ inhibitors, ATN-161 [7]. So far, no drugs are selective for ITGB4 in tumor therapy [8]. The identification of compounds that are highly selective for ITGB4 high-expressing cancer cells has been advancing but challenging. 
We have been investigating the roles of ITGB4 in vascular endothelium cell (VEC) apoptosis. Increased ITGB4 level was accompanied by VEC apoptosis elicited by atorvastatin [9], deprivation of growth factors [10], safrole oxide [11], and a complex of copper and salicylaldehyde [12]. A derivative of isochroman (ISO-9) and low concentrations of cadmium inhibited VEC apoptosis by decreasing the level of ITGB4 [13, 14]. We found that ITGB4 level in VECs was very low in the presence of serum and fibroblast growth factor 2 (FGF-2) and was increased with their absence [10]. A small molecule, ECPC, promoted VEC apoptosis by stimulating ITGB4 nuclear translocation when ITGB4 was upregulated by deprivation of serum and FGF-2 [15]. However, the mechanisms by which ITGB4 enters the nucleus and triggers pro-apoptosis gene expression are not clear.

ITGB4 is distinguished by its large cytoplasm domain containing several phosphorylation sites at serine and tyrosine residues, which is essential for ITGB4 to be signaling-competent. Protein kinase $\mathrm{C}-\alpha(\mathrm{PKC} \alpha)$ accounts for the phosphorylation of key serine residues (S1356, S1360, S1364), which contributes to HD disassembly $[16,17]$. The phosphorylation of multiple ITGB4 tyrosine residues is mainly responsible for signaling transduction. Y1440 and Y1526 phosphorylation recruits Shc and thereby activates Ras-extracellular signal-regulated kinase (Ras-ERK) signaling [18]. ITGB4 Y1494 controls anchorage-independent tumor growth by activating ERK1/2 signaling and invasion by activating PI3K and Src [19]. Y1494 has been identified as a master regulator of ITGB4 phosphorylation and signaling. Mutation of Y1494 suppressed overall tyrosine phosphorylation of ITGB4 subunit [20].

Annexin A7 (ANXA7) is a $\mathrm{Ca}^{2+}$-dependent, phospholipid-binding protein and unique for its extraordinary long amino terminus [21]. ANXA7 is predominantly localized in cytoplasm, and translocates to the plasma membrane, nuclear membrane and vesicular structures in response to altered $\mathrm{Ca}^{2+}$ concentration [22, 23]. ANXA7, via its GTPase activity, facilitates vesicle transport and membrane fusion [24]. In addition, ANXA7 may function in carcinogenesis by a discrete signaling pathway involving some tumor-suppressor, DNA-repair, and apoptosis-related genes [25, 26]. We previously found a small molecule, $\mathrm{ABO}$, that could inhibit the GTPase activity of ANXA7 [27]. In the apoE $\mathrm{E}^{-/-}$mouse endothelium, ABO inhibited the binding of ANXA7 and ITGB4 and decreased ITGB4 Y1494 phosphorylation [28]. So ANXA7 may be involved in regulating the phosphorylation and nuclear translocation of ITGB4.

Inspired by the previous studies and given that ITGB4 is highly expressed in cancer cells, in the current study we focused on the roles of ITGB4 nuclear translocation in controlling cancer cell apoptosis.
We discovered a chiral small molecule, SEC, that could specifically induce apoptosis of tumor cells with high ITGB4 content by promoting ITGB4 nuclear translocation. We provide new evidence that nuclear ITGB4 can bind to the $A T F 3$ promoter region and then activate transcription of downstream genes. We further demonstrated that with increased GTPase activity, ANXA7 was involved in ITGB4 nuclear translocation by increasing the phosphorylation of the ITGB4 Y1494 site. This study provides a powerful proof of concept for using the nuclear translocation of ITGB4 as a therapeutic strategy to combat various ITGB4-related cancers.

\section{RESULTS}

\section{SEC specifically induces apoptosis in tumor cells with high expression of ITGB4 by promoting ITGB4 nuclear translocation}

ITGB4 was initially identified as a tumor-related antigen upregulated in multiple cancer cells [2], so investigating compounds selective for ITGB4 for cancer therapy is of interest. We used the structure of ECPC to generate an effective chiral small molecule, (S)-ethyl 1-(3-(4-chlorophenoxy)-2-hydroxypropyl)-3(4-methoxyphenyl)-1H-pyrazole-5-carboxylate (SEC) (Figure 1A), that selectively inhibited growth of cells with high ITGB4 content. We examined its selectivity for inducing apoptosis in cells with differential expression of ITGB4: hepatic cells (L-02), human embryonic kidney cells (HEK293), and 4 kinds of tumor cells - prostatic cancer (PC3), lung carcinoma (A549), colorectal cancer (HCT116) and breast cancer (MCF-7) (Figure 1B). ITGB4 level was low in L-02 cells, and SEC had no effect on their viability (Figure 1C). Similarly, the viability of HEK293 cells, with low ITGB4 level, was not affected by SEC treatment (Figure 1D). However, SEC significantly decreased the viability of HEK293 cells with overexpression of ITGB4 (Figure 1D). ITGB4 is abundant in the 4 kinds of tumor cells, and SEC dose-dependently decreased the cell viability (Figure $1 \mathrm{E}$ and $1 \mathrm{~F}$ ). In parallel with the marked decrease in cell viability, Hoechst staining revealed that SEC augmented the apoptosis ratio of the tumor PC3, A549, HCT116 and MCF-7 cells (Supplementary Figure 1A and 1B).

Altered localization of the transmembrane receptor ITGB4 is implicated in the progression of carcinoma $[3,5,6]$. The critical roles of ITGB4 localization inspired us to detect the effect of SEC on the subcellular distribution of ITGB4. We used HEK293, which stably express GFP-ITGB4, and A549 cells, with high ITGB4 level. SEC time-dependently triggered ITGB4 nuclear translocation in GFP-ITGB4-expressing HEK293 cells (Figure 1G). The altered distribution of ITGB4 to the nucleus was also confirmed in A549 cells (Figure 1H). 


\section{Nuclear ITGB4 regulates the transcription of target genes}

The nuclear redistribution of ITGB4 prompted us to search for potential target genes that might be regulated by nuclear ITGB4. Therefore, we performed microarray assay to analyze the gene expression profile with ITGB4 nuclear translocation triggered by SEC. Microarray assay revealed increased expression of a number of apoptosisrelated genes. We selected the most upregulated genes, CITED2, PPP1R15A, IL8, ATF3 and TRIB3 (Table 1), for further investigation. Oligonucleotide primers for the genes of interest were designed (Supplementary Table 1). The mRNA levels of PPP1R15A, IL8, ATF3 and TRIB3 were indeed increased with SEC stimulation (Figure 2A-2E), with negligible effect on CITED2 transcription (Supplementary Figure 2A). After RNAi-mediated knockdown of ITGB4, SEC stimulation had no effect on the expression of target genes (Figure 2F-2I and Supplementary Figure 2B).
$A T F 3$ is needed for full induction of PPP1R15A expression [29]. Loss of $A T F 3$ function blocked the transcription of IL8 [30]. Increased $A T F 3$ level is accompanied by the upregulation of TRIB3 during apoptosis [31, 32]. Therefore, nuclear ITGB4 might promote apoptosis by binding to the $A T F 3$ promoter region, thereby promoting the expression of $A T F 3$ and upregulating downstream apoptosis-related genes. To test this hypothesis, we predicted 8 binding sites $2-\mathrm{kb}$ upstream of the $A T F 3$ promoter region and performed chromatin immunoprecipitation (ChIP) to detect ITGB4 occupancy at each of the 8 putative regions with primers specific for the predicted regions (Supplementary Table 2). Consistently, semiquantitative RT-PCR and quantitative RT-PCR (qPCR) confirmed that SEC activated the recruitment of ITGB4 to the sixth predicted binding site (Figure 2J and 2K), with no binding ability with the other 7 sites (Supplementary Figure 2C). These results indicate the binding of ITGB4 to the promoter of $A T F 3$ in the upregulation of $A T F 3$ and the downstream gene transcription.
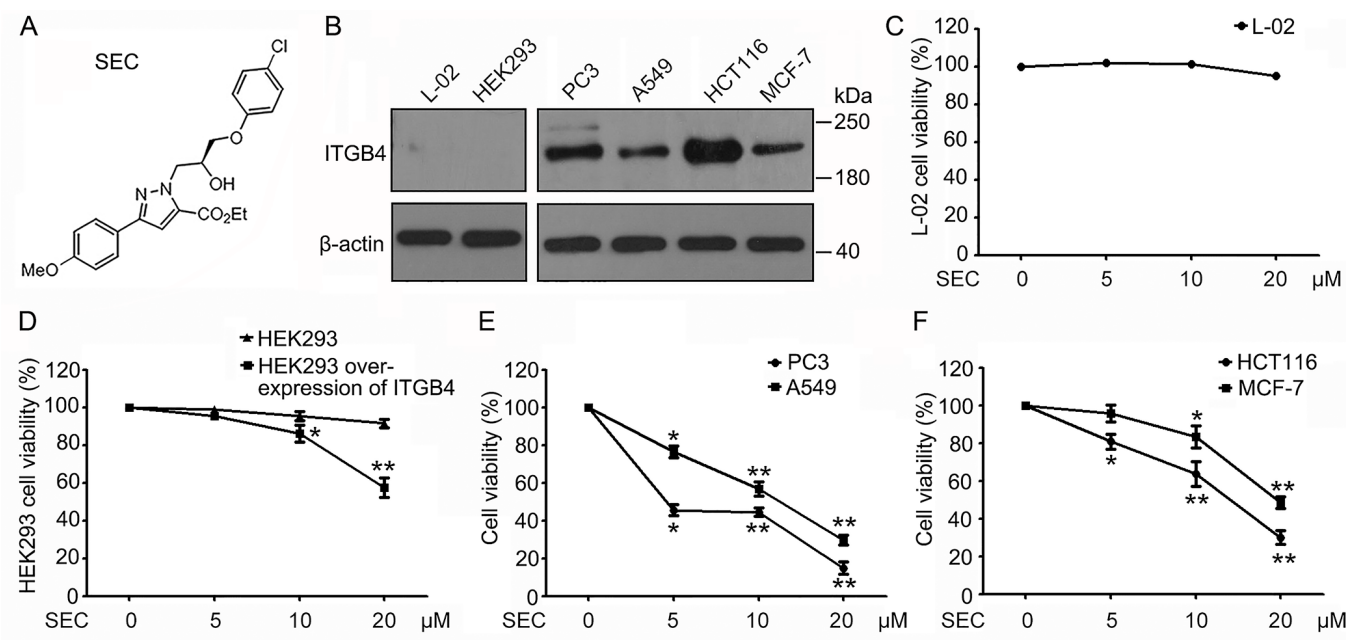

E

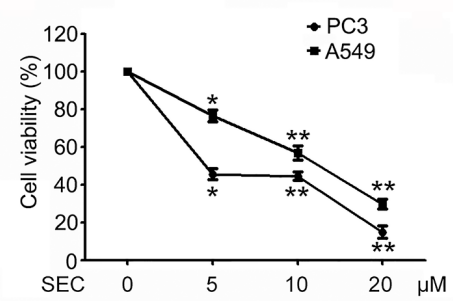

F
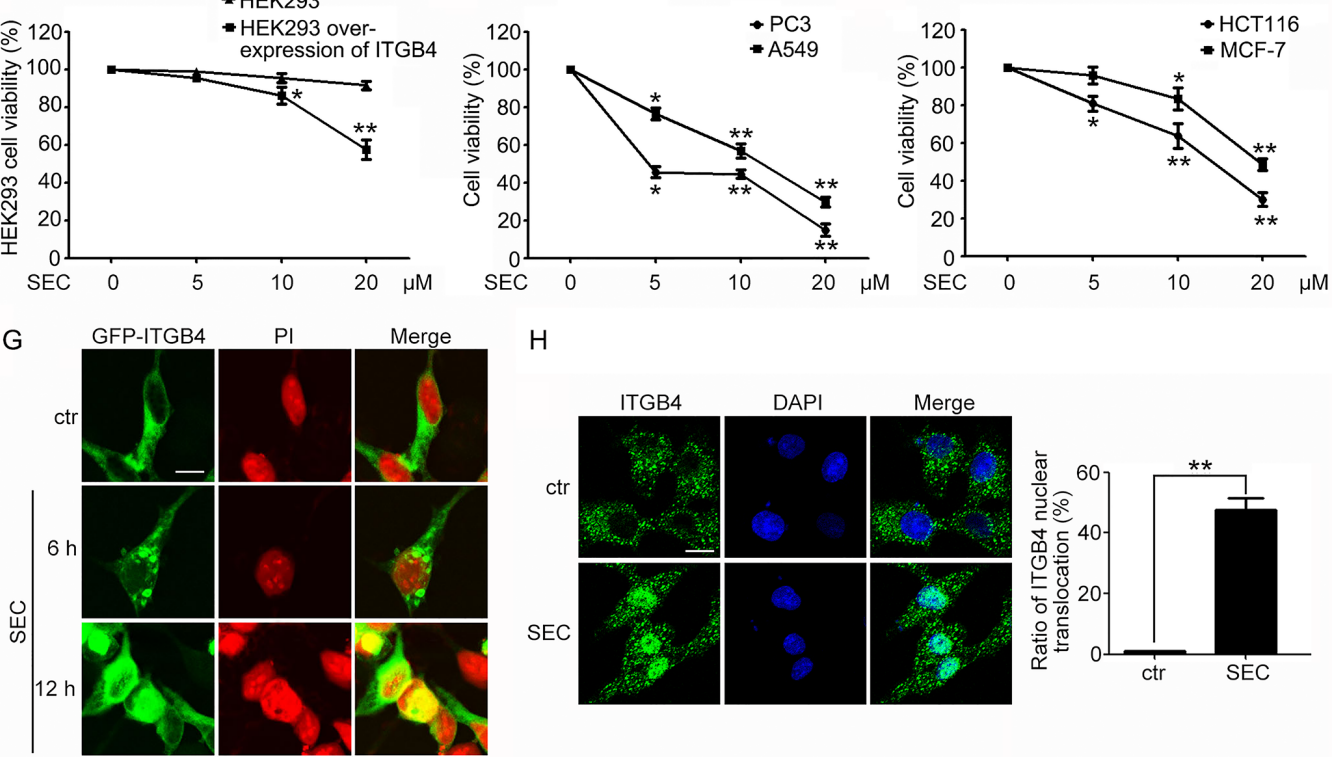

$\mathrm{H}$
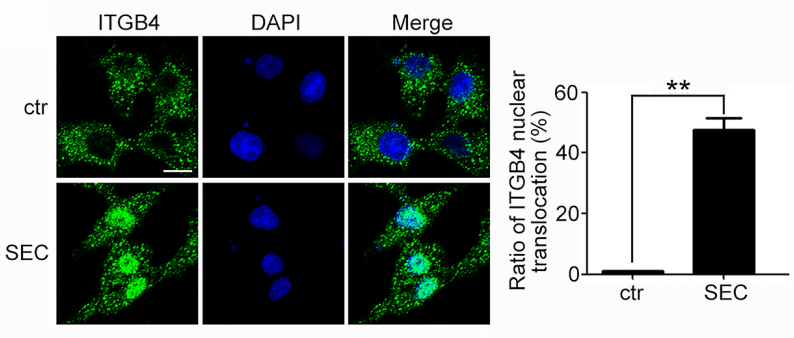

Figure 1: Effect of a chiral small molecule, SEC, on cell viability and ITGB4 nuclear translocation in cells with different expression of ITGB4. (A) The structure of SEC. (B) Western blot analysis of ITGB4 protein level in L-02, HEK293, PC3, A549, HCT116 and MCF-7 cells. $\beta$-actin was a loading control. Viability of (C) L-02 cells, (D) HEK293 cells and HEK293 cells with ITGB4 overexpressed, (E) PC3 cells and A549 cells, and (F) HCT116 and MCF-7 cells treated with SEC at the indicated concentrations for $24 \mathrm{~h}$. (G) HEK293 cells were transfected with GFP-ITGB4 for $24 \mathrm{~h}$, then treated with $20 \mu \mathrm{M}$ SEC for $6 \mathrm{~h}$ and $12 \mathrm{~h}$, and GFP-ITGB4 localization was detected by the Zeiss ZEN software. Nuclei were labeled with propidium iodide (PI). (H) Immunofluorescence to show the effect of SEC on ITGB4 nuclear translocation at $20 \mu \mathrm{M}$ for $12 \mathrm{~h}$ in A549 cells. Nuclei were labeled with 4',6-diamidino-2-phenylindole (DAPI). Statistical analysis shows the ratio of ITGB4 nuclear translocation. Bar, $16 \mu \mathrm{M}$. Data are mean \pm SEM; $n=3 ;{ }^{*} p<0.05 ;{ }^{* *} p<0.01$. 
Table 1. Microarray analysis shows the five most upregulated genes

\begin{tabular}{|c|c|l|}
\hline \multicolumn{2}{|c|}{ Gene symbol } & \multicolumn{1}{c|}{ Gene name } \\
\hline$C I T E D 2$ & 9.4115 & Cbp/p300-interacting transactivator 2 \\
\hline$P P P 1 R 15 A$ & 9.0298 & Protein phosphatase 1, regulatory subunit 15A \\
\hline$I L 8$ & 8.4076 & Interleukin-8 precursor \\
\hline$A T F 3$ & 7.71255 & Activating transcription factor 3 \\
\hline$T R I B 3$ & 7.1499 & Tribbles homolog 3 \\
\hline
\end{tabular}

A

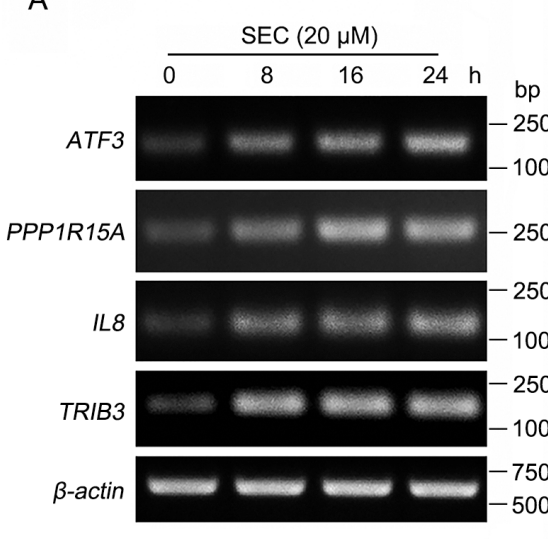

F
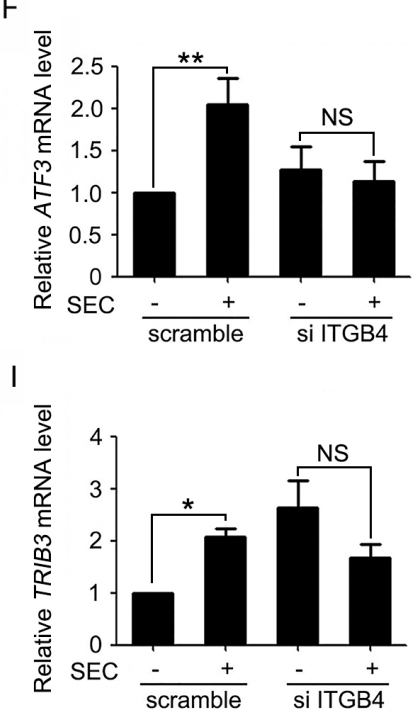

B
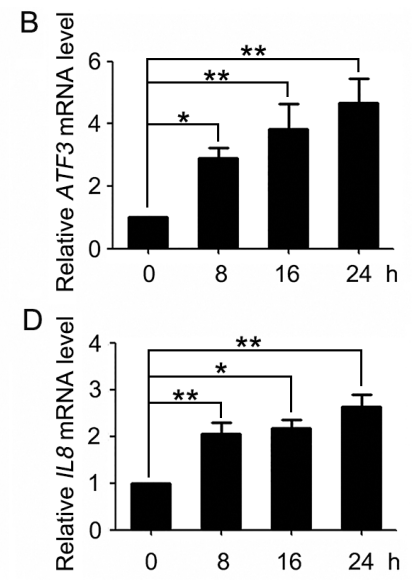

G

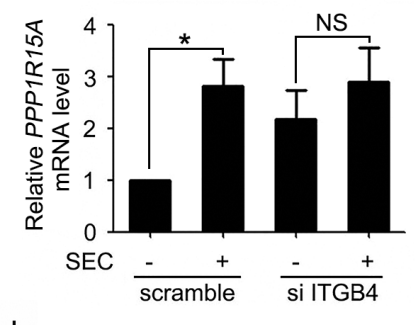

$\mathrm{J}$

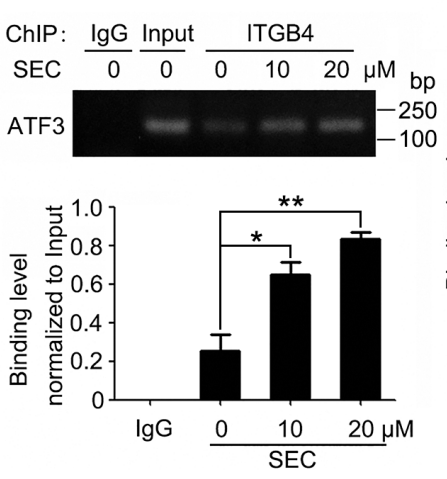

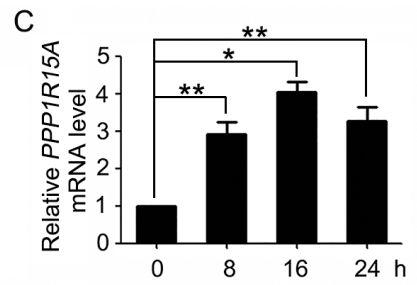

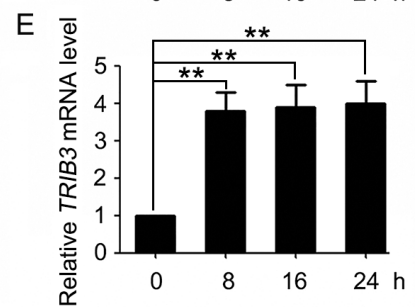

$\mathrm{H}$

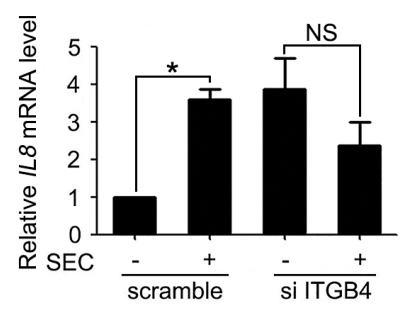

K

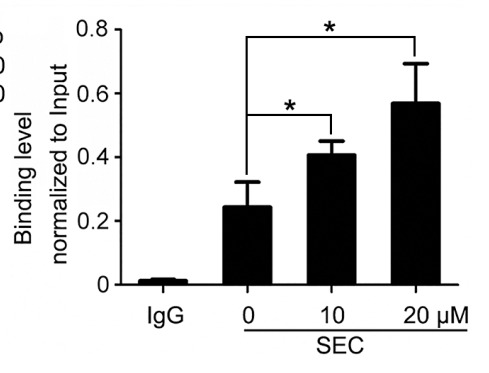

Figure 2: Activation of gene expression by nuclear ITGB4. (A) RT-PCR analysis of mRNA levels of ATF3, PPPIR15A, IL8 and TRIB3 treated with SEC $(20 \mu \mathrm{M})$ for indicated times. (B, C, D and E) Quantified bands of Figure 2A using ImageJ. mRNA levels were normalized to that of $\beta$-actin. (F, G, H and I) qPCR analysis of mRNA levels of ATF3, PPP1R15A, IL8 and TRIB3 treated with SEC $(20 \mu \mathrm{M})$ for $24 \mathrm{~h}$ with or without ITGB4 siRNA. (J and K) Effects of SEC treatment on the binding of ITGB4 to the ATF3 promoter. PC3 cells treated with SEC were crosslinked, fractionated, and submitted to (J) ChIP-PCR and (K) ChIP-qPCR analysis. Band density was quantified by using ImageJ. Data are mean \pm SEM; $n=3 ;{ }^{*} p<0.05 ; *^{*} p<0.01$; NS, no significance. 


\section{ANXA7 is involved in ITGB4 nuclear translocation}

To illuminate the mechanism by which ITGB4 translocated to the nucleus, we investigated the key regulatory factors. We performed co-immunoprecipitation assay with PC3 cells and found that SEC dose-dependently promoted the binding of ANXA7 to ITGB4 (Figure 3A). Therefore, ANXA7 may participate in the nuclear translocation of ITGB4.

To test this hypothesis, we performed biochemical fractionation with PC3 cells after treatment with ANXA7 siRNA for $24 \mathrm{~h}$ followed by SEC stimulation for $24 \mathrm{~h}$. The efficiency of ANXA7 knockdown was analyzed by western blot analysis (Supplementary Figure 3A), which was concomitant with minor levels of nuclear
ITGB4 (Figure 3B). As well, on immunofluorescence analysis, treatment with ANXA7 siRNA blocked the capacity of SEC to induce nuclear localization of ITGB4 (Figure 3C, 3D and Supplementary Figure 3B). This finding suggests that ANXA7 is responsible for ITGB4 nuclear translocation.

\section{ANXA7 promotes ITGB4 nuclear translocation by exerting GTPase activity}

Given that ANXA7 possesses GTPase property, we wondered whether ANXA7 contributed to ITGB4 redistribution by exerting its GTPase activity. ABO inhibits ANXA7 GTPase activity by decreasing phosphorylation at ANXA7 Thr286 with no effect on phosphorylation at Thr275 [27]. We found that $\mathrm{ABO}$ inhibited the
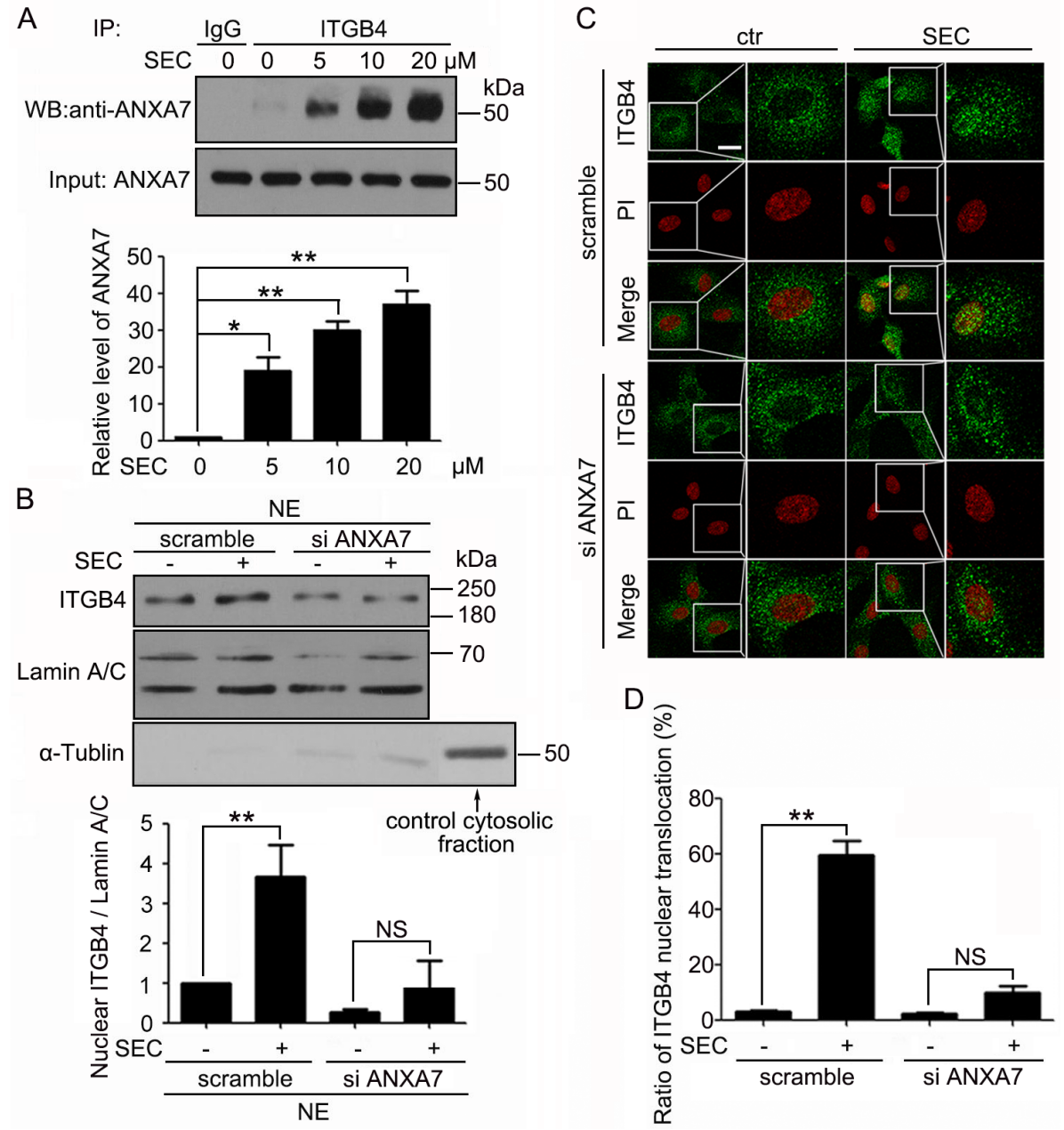

Figure 3: ANXA7 binds to ITGB4 and is required for ITGB4 nuclear translocation. (A) Western blot (WB) analysis of co-immunoprecipitation (co-IP) of ANXA7 with ITGB4 antibody in PC3 cells treated with SEC at the indicated concentrations with $1 \%$ fetal bovine serum (FBS) for $24 \mathrm{~h}$ and quantification of ANXA7 level. (B) Subcellular fractionation of PC3 cells to detect nuclear ITGB4 level after treatment with SEC at $20 \mu \mathrm{M}$ for $24 \mathrm{~h}$ with and without siRNA ANXA7. WB analysis of Lamin A/C and $\alpha$-Tubulin to confirm the specificity of the cell fractionation protocol. The nuclear marker Lamin A/C was a loading control. (C and D) Immunofluorescence analysis of localization of ITGB4 in A549 cells transfected with and without ANXA7 siRNA for $24 \mathrm{~h}$, then treated with $20 \mu \mathrm{M}$ SEC for $12 \mathrm{~h}$ with $1 \%$ FBS, and the percentage of cells containing nuclear ITGB4. Nuclei were labeled with PI. Bar, $16 \mu \mathrm{M}$. Data are mean \pm SEM; $n=3$; ${ }^{*} p<0.05 ; * * p<0.01 ; \mathrm{NS}$, no significance. 
SEC-promoted binding of ANXA7 and ITGB4 (Figure 4A and 4B). SEC stimulated the co-precipitation of ITGB4 with mCherry-ANXA7-wt (wild type) and -mt1 (T275A) (mutant) but not non-phosphorylatable mCherryANXA7-mt2 (T286A). mCherry-ANXA7-mt3 (T286D), a phospho-mimic mutant, facilitated the binding of ITGB4 and ANXA7 (Supplementary Figure 4A). In agreement, immunofluorescence assay revealed that SEC facilitated the co-localization of the 2 proteins, and ABO effectively reversed the phenomenon (Figure 4C and Supplementary Figure 4B). Next, we explored the function of ANXA7 GTPase in ITGB4 nuclear translocation. On immunofluorescence and subcellular fractionation assay, SEC-triggered ITGB4 nuclear translocation was compromised with ABO treatment (Figure 4D, 4E and Supplementary Figure 4C).

In addition, as ITGB4 nuclear translocation was suppressed by ABO, the decreased PC3 cell viability induced by SEC was attenuated (Supplementary Figure 4D). With ABO treatment, the SEC-increased $A T F 3$ gene expression was compromised, accompanied by decreased expression of PPP1R15A, IL8 and TRIB3 (Supplementary Figure 4E).

For the vital importance of ANXA7 GTPase activity in the stimulation of ITGB4 nuclear trafficking, we evaluated the effect of SEC on ANXA7 GTPase activity. We transfected HEK293 cells with plasmids encoding 6his-ANXA7 and 6his-ANXA7-mt1 (T275A)
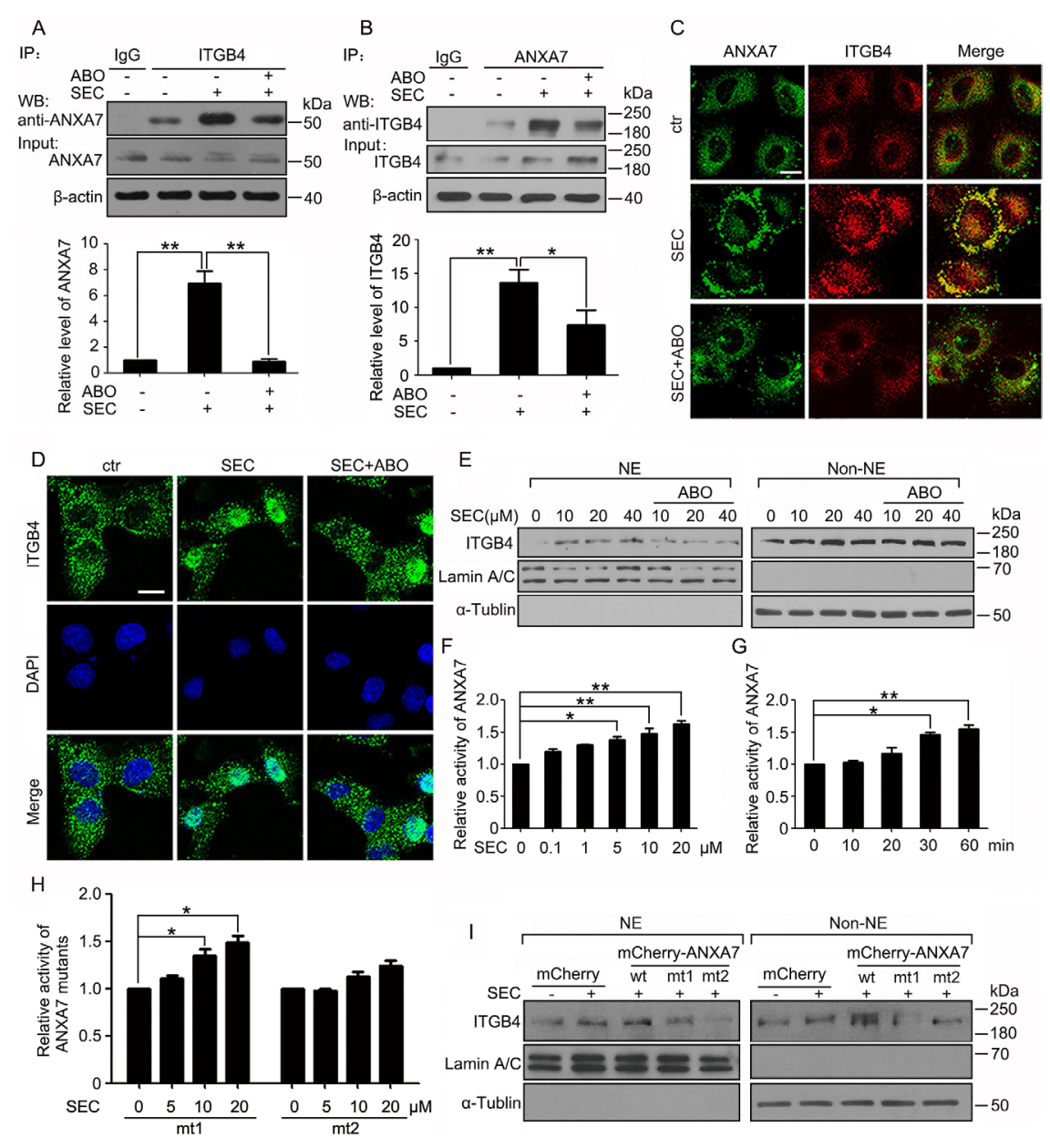

Figure 4: ANXA7 GTPase activity promotes ITGB4 nuclear translocation. WB analysis of co-IP of (A) ANXA7 with ITGB4 antibody and (B) ITGB4 with ANXA7 antibody in PC3 cells treated with SEC $(20 \mu \mathrm{M})$ with or without ABO $(50 \mu \mathrm{M})$ with $1 \%$ FBS for $24 \mathrm{~h}$ and quantification of co-immunoprecipitated ANXA7 and ITGB4 levels. (C) Immunofluorescence assay of the co-localization of ANXA7 and ITGB4 treated with SEC $(20 \mu \mathrm{M})$ with or without ABO $(50 \mu \mathrm{M})$ for $6 \mathrm{~h}$. (D) Immunofluorescence of ITGB4 in A549 cells incubated with SEC $(20 \mu \mathrm{M})$ with or without ABO $(50 \mu \mathrm{M})$ for $12 \mathrm{~h}$. Nuclei were labeled with DAPI. (E) WB analysis of nuclear translocation of ITGB4 after subnuclear fractionation of PC3 cells treated with SEC at the indicated concentrations with or without ABO (50 $\mu \mathrm{M})$ for $24 \mathrm{~h}$. (F and G) Dose-dependent effect of SEC on ANXA7 GTPase activity with incubation for 60 min, and time-dependent effect at $20 \mu \mathrm{M}$. (H) Effect of SEC on ANXA7-mt1 (T275A) and -mt2 (T286A) GTPase activity at the indicated concentrations for 60 min. (I) WB analysis of localization of nuclear and cytoplasmic ITGB4 in PC3 cells transfected with expression vectors mCherry and mCherry-ANXA7-wt, -mt1 (T275A) and -mt2 (T286A) for $48 \mathrm{~h}$, then treated with $20 \mu \mathrm{M} \mathrm{SEC} \mathrm{for} 24 \mathrm{~h}$ with $1 \%$ FBS. NE and Non-NE, nucleus and non-nucleus components, respectively. Bar, $16 \mu \mathrm{M}$. Data are mean \pm SEM; $n=3 ;{ }^{*} p<0.05 ; * * p<0.01$. 
and -mt2 (T286A) mutants for $48 \mathrm{~h}$. SEC dose- and time-dependently increased the activity of 6his-ANXA7 purified from HEK293 cells (Figure 4F and 4G). The point mutation to alanine at Thr275 had no effect on SEC-increased ANXA7 activity (Figure $4 \mathrm{H}$ and Supplementary Figure 5A). In contrast, with mutation of Thr286 to alanine, SEC could not increase ANXA7 GTPase activity (Figure $4 \mathrm{H}$ and Supplementary Figure 5A).

After transfecting HEK293 cells with plasmids coding for mCherry-ANXA7-wt, -mt1 (T275A) and -mt2 (T286A) and GFP-ITGB4 for $48 \mathrm{~h}$, we used antibodies specific for ANXA7 and ITGB4 to immunoprecipitate ANXA7 and ITGB4 fusion proteins, respectively, and examined whether SEC interfered in the process. SEC dose-dependently blocked the binding of mCherryANXA7-wt and -mt1 (T275A) to their antibodies (Supplementary Figure 5B and 5C) but had no effect on the binding of mCherry-ANXA7-mt2 (T286A) with its antibody (Supplementary Figure 5D). Moreover, SEC did not interfere with the binding of GFP-ITGB4 to its antibody (Supplementary Figure 5E). When we immunoprecipitated mCherry-ANXA7-wt with mCherry antibody, the level of immunoprecipitated mCherry-ANXA7-wt was not changed with SEC treatment (Supplementary Figure 5F), and the level of immunoprecipitated GFP-ITGB4 with GFP antibody was not changed (Supplementary Figure 5G). Therefore, SEC selectively and directly bound to ANXA7 but not ITGB4. Thr286 in ANXA7 was a key binding site. SEC increased ANXA7 GTPase activity by binding to ANXA7 at Thr286.

Subcellular fractionation analysis revealed that PC3 cells transfected with mCherry-ANXA7-mt2 (T286A) expressed extreme low levels of nuclear ITGB4 as compared with cells transfected with mCherry-ANXA7-wt and -mt1 (T275A) (Figure 4I). These results reinforced the importance of ANXA7 GTPase activity in controlling ITGB4 nuclear translocation.

\section{ANXA7 GTPase activity enhances ITGB4 Y1494 phosphorylation and its subsequent nuclear translocation}

Tyr1494 in ITGB4 functions as a master regulator controlling multiple signal transduction pathways closely related to tumor progression $[15,19,20]$. To detect the role of Y1494 in ITGB4 nuclear trafficking, we transfected HEK 293 cells with wild-type ITGB4 and ITGB4 containing a point mutation to alanine at Y1494. ITGB4 nuclear localization was reduced more in cells with expression of the Y1494A mutant than wild-type ITGB4 (Figure 5A). On immunofluorescence assay, SEC clearly induced nuclear translocation of the wild-type ITGB4 but had little effect on the Y1494A mutant (Figure 5B).
To confirm the contribution of ANXA7 in regulating the phosphorylation of ITGB4, we transfected ANXA7 siRNA into PC3 cells and showed that Y1494 phosphorylation of ITGB4 was markedly inhibited by blocking ANXA7 expression (Figure 5C and 5D). Because SEC increased and ABO decreased ANXA7 GTPase activity, SEC elevated the phosphorylation status at ITGB4 Y1494, which was inhibited by ABO (Figure 5E and 5F). In addition, phosphorylation of ITGB4 Y1494 was lower in PC3 cells transfected with mCherry-ANXA7-mt2 (T286A) than mCherry-ANXA7-wt (Figure 5G and 5H). Thus, by exerting GTPase activity, ANXA7 promoted ITGB4 Y1494 phosphorylation and its subsequent nuclear translocation induced by SEC.

\section{SEC inhibited the growth of human tumor xenografts in an avian embryo model}

Next, we determined whether SEC had apoptosispromoting effects in vivo. Because of the immune-deficient environment and the dense capillary network, the chick embryo chorioallantoic membrane (CAM) is widely used for tumor engraftment to evaluate the efficacy of anticancer drugs $[33,34]$ and for the action of proangiogenic or antiangiogenic factors [35]. Therefore, we used the CAM model to study the action of SEC in tumor growth as well as normal angiogenesis. A549 cells were deposited on the CAM and formed a solid tumor within 2 days. The solid adenocarcinoma was locally treated from day 2 to 8 with PBS or PBS containing SEC every 2 days. Treatment with PBS plus SEC substantially inhibited tumor growth as compared with PBS alone (Figure 6A). $5 \mathrm{FU}$ treatment was beneficial in reducing the size of xenografts (Supplementary Figure 6). TUNEL assay of frozen sections of tumors revealed that SEC effectively promoted apoptosis in vivo, and an even stronger signal was detected in the peritumoral edge (Figure 6B). To determine whether SEC disturbed normal angiogenesis accompanied by suppressing tumor growth, we directly measured the angiogenic action of SEC on CAM. SEC had no effect on CAM normal angiogenesis (Figure 6C). Fully consistent with the in vivo angiogenesis studies, SEC did not interfere with the formation of capillary-like tube structures with serum and FGF-2 in vitro Matrigel assay (Figure 6D). Therefore, SEC effectively inhibited tumor growth in vivo by inducing apoptosis with no adverse effects on normal CAM angiogenesis.

\section{DISCUSSION}

In this study, we identified a new chiral small molecule, SEC, that could promote cancer cell apoptosis by inducing ITGB4 nuclear translocation. We provide the novel function of ITGB4 in the nucleus by binding to the 
ATF3 promoter and demonstrate the regulatory roles of ANXA7 in ITGB4 nuclear trafficking by promoting the phosphorylation of ITGB4 Y1494.

ITGB4 is highly expressed in multiple tumors, such as lung carcinoma, prostate cancer, colorectal cancer and breast cancer [2], and is implicated in clinical investigation [36]. Most studies have focused on the involvement of ITGB4 in tumor proliferation, invasion and metastasis. Here, we highlight the physiological significance of ITGB4 nuclear translocation in promoting tumor cell apoptosis. Unlike blood vessels delivering abundant nutrients to healthy tissues, tumor vasculature is tortuous and leaky, functions poorly and results in a nutrient-limited hostile tumor microenvironment [37, 38]. In this study, we investigated the action of SEC in a more physiological microenvironment with low serum in tumor cells and appropriate serum in normal cells. Strikingly, SEC specifically promoted apoptosis by inducing ITGB4 nuclear translocation in a tumor-specific manner, with no side effects in normal cells.

All of the genes upregulated in response to SEC have potential links with apoptosis. ATF3 has low expression in normal cells and upregulated with stress signals involved in apoptosis [39-41]. Accumulating studies indicate that $A T F 3$ may work as a master regulator controlling the expression of PPP1R15A [29, 42], IL8 [30] and TRIB3 [31, 32, 43, 44]. Our ChIP results showed that nuclear ITGB4 bound to the promoter region of $A T F 3$. The significant and specific SEC-induced binding of ITGB4 to the $A T F 3$ promoter activates $A T F 3$ transcription and explains the increased expression of the downstream genes PPP1R15A, IL-8 and TRIB3. Hence, we provide the novel roles of nuclear ITGB4 in stimulating the transcription of target genes.

Use of the PSORT II prediction program (http://psort.hgc.jp/form2.html) revealed that ITGB4 possesses 2 putative polybasic nuclear localization signals (NLSs) - aa 700-HKKK-705 and 1662-RPRR-1667. Emerging evidence has shown that transmembrane proteins, such as receptor tyrosine kinases (RTKs) and p75 neurotrophic receptor, can translocate from the cell membrane to the nucleus [45-48]. EGFR and ErbB2 migrate to the nucleus by endocytosis and binding to importin $\beta 1$ via NLSs. The activation of dynamin and Ran GTPases is required for endocytic internalization and trafficking $[49,50]$. ANXA7, via its GTPase activity, facilitates membrane vesicle fusion during endocytosis and exocytosis [24, 51, 52]. Here we confirmed that SEC-activated ANXA7 GTPase was responsible for promoting ITGB4 nuclear transport.

The phosphorylation of ITGB4 cytoplasmic domain could contribute to the changes in ITGB4

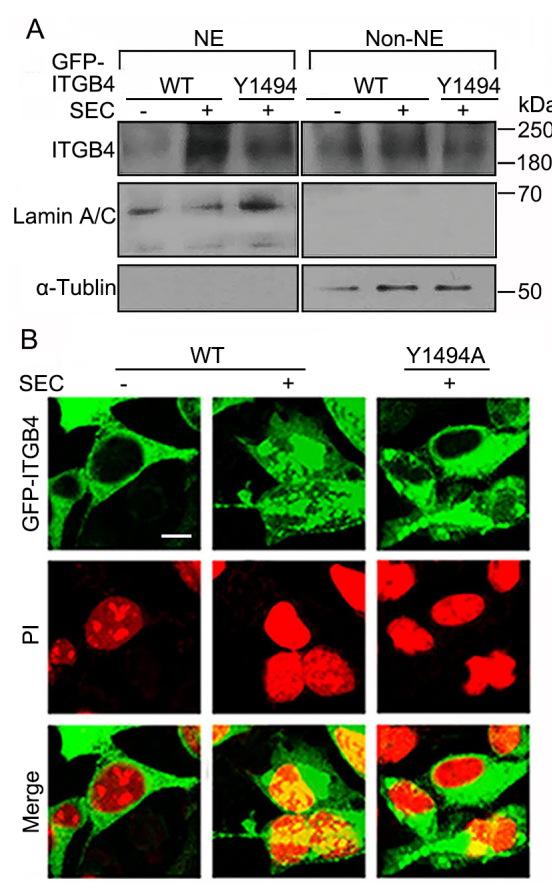

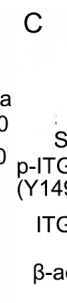

C

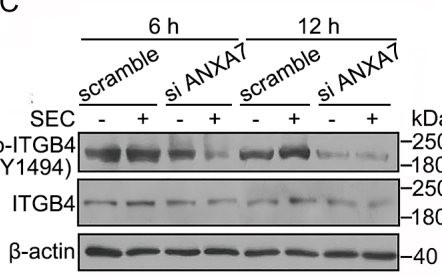

E
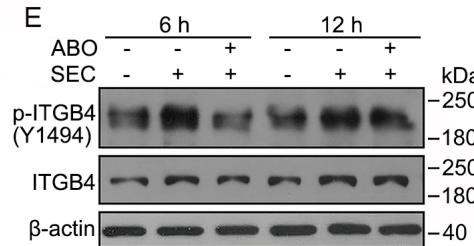

G

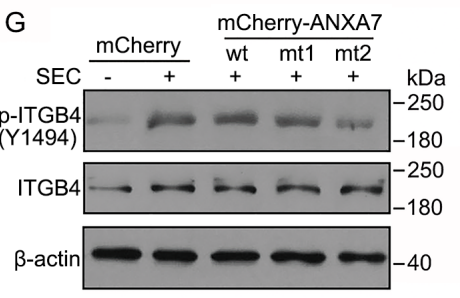

D

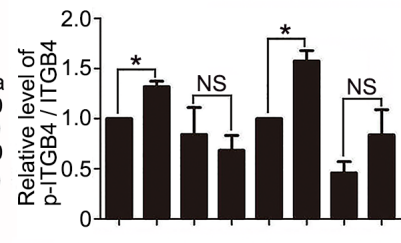

$\mathrm{F}$

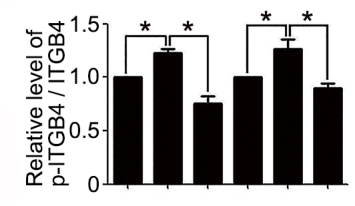

$\mathrm{H}$

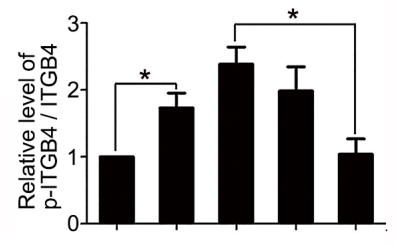

Figure 5: Y1494 phosphorylation of ITGB4 by ANXA7 is responsible for its nuclear translocation. Transfection of HEK293 cells with GFP-ITGB4 (WT) or GFP-ITGB4-mt (Y1494A) for $24 \mathrm{~h}$, followed by $20 \mu \mathrm{M}$ SEC treatment for $24 \mathrm{~h}$. (A) WB analysis of nuclear translocation of ITGB4 after subnuclear fractionation. NE and Non-NE, nucleus and non-nucleus components, respectively. (B) Immunofluorescence of ITGB4 nuclear translocation. Nuclei were labeled with PI. WB analysis of phosphorylated ITGB4 at Y1494 and total ITGB4 in PC3 cells treated with SEC $(20 \mu \mathrm{M})(\mathbf{C}$ and $\mathbf{D})$ with or without siRNA ANXA7 and $(\mathbf{E}$ and $\mathbf{F})$ with or without ABO $(50 \mu \mathrm{M})$ for the indicated times and $(\mathbf{G}$ and $\mathbf{H})$ with expression vectors mCherry and mCherry-ANXA7-wt, -mt1 (T275A) and -mt2 (T286A) for $12 \mathrm{~h}$, and the quantification of phosphorylated ITGB4 at Y1494. Bar, $16 \mu \mathrm{M}$. Data are mean $\pm \mathrm{SEM} ; n=3$; ${ }^{*} p<0.05$; NS, no significance. 
localization. PKC-mediated phosphorylation of S1356, S1360 and S1364 leads to HD disruption and ITGB4 mobilization to lamellipodia [3, 17]. ITGB4 phosphorylation at S1354 and S1362 causes ITGB4 endocytosis via Rab5 and Rab11 compartments [53]. Moreover, EGFR nuclear transport is initiated by the phosphorylation of Y1101 and S229 [54, 55]. Here, we revealed that ANXA7 activation resulted in
Y1494 phosphorylation of ITGB4, which triggered ITGB4 redistribution to the nucleus. The activated GTPase family is widely implicated in promoting target phosphorylation via intermediate kinases. Rac1 GTPase activation promotes phosphorylation of myosin II heavy chain on Ser1916 in a PKC-dependent mechanism that enhances cell migration [56]. Rho-associated protein kinase (ROCK) is an effector of the small GTPase family

A

SEC

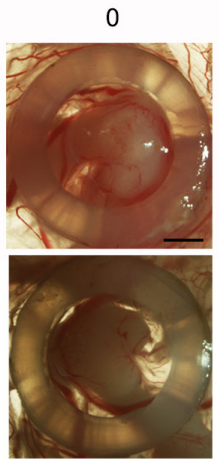

$0.2 \mu \mathrm{M} / 20 \mu \mathrm{l}$

$0.5 \mu \mathrm{M} / 20 \mu \mathrm{I}$
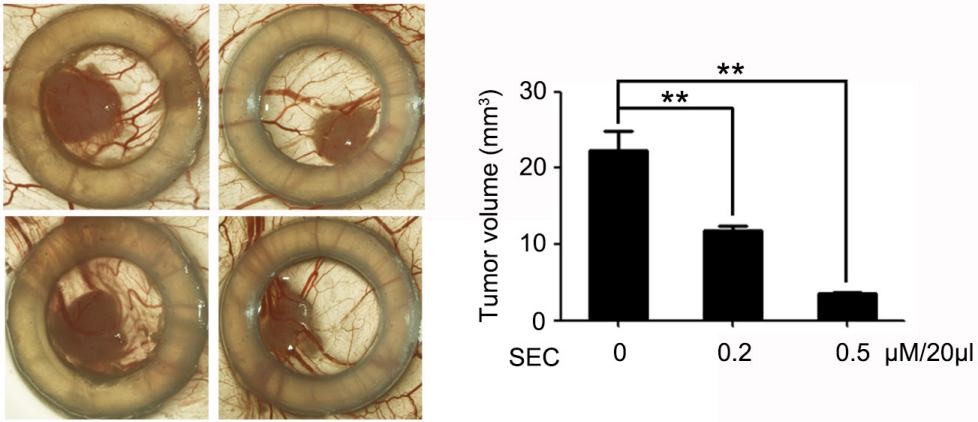

B

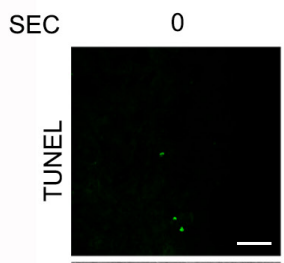

$0.2 \mu \mathrm{M} / 20 \mu \mathrm{l}$
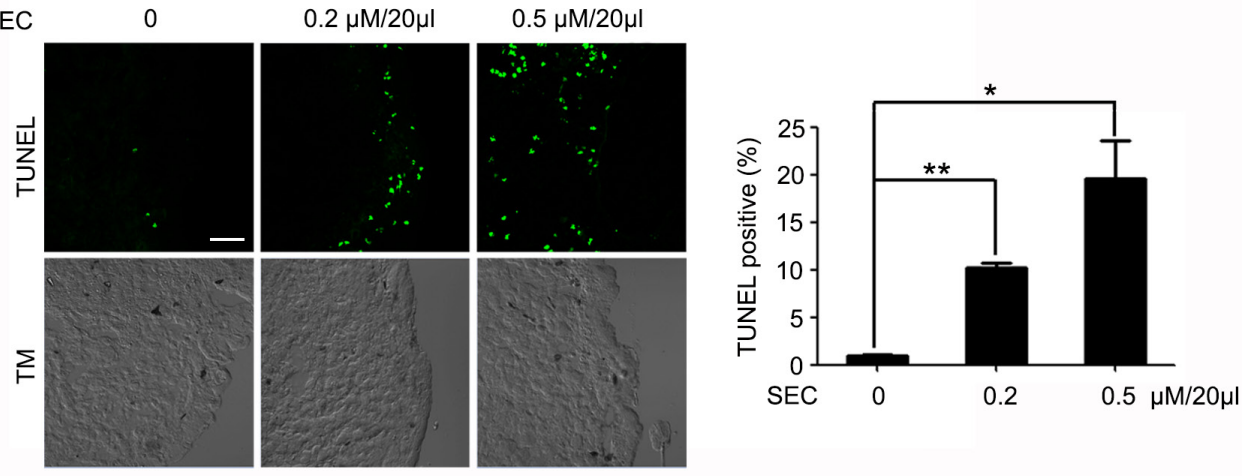

C

SEC
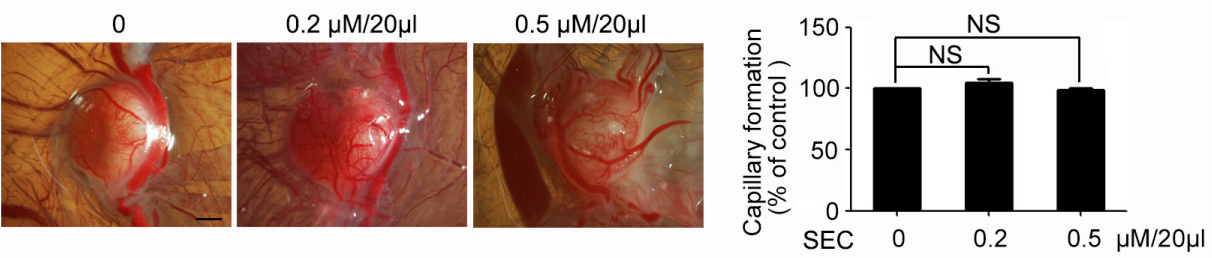

D

SEC 0
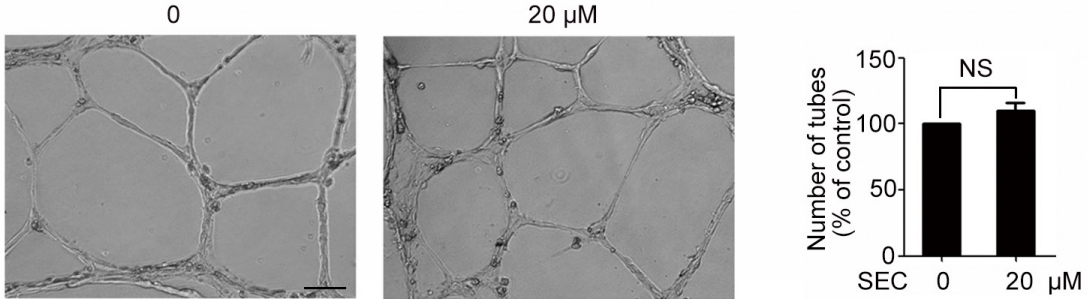

Figure 6: Topical treatment of experimental tumor with SEC. (A) Biomicroscopy imaging of control and treated tumors. Tumor volumes were quantified. Control group show progressive growth, whereas SEC-treated tumors show smaller tumor volume. Bar, $1.5 \mathrm{~mm}$. $n=5$. (B) TUNEL staining and confocal microscopy analysis of the frozen sections of Day 8 experimental tumors. Apoptotic rate with and without SEC treated was quantified by TUNEL staining. Bar, $32 \mu \mathrm{M} . n=5$. (C) Biomicroscopy and quantification of angiogenesis on gelatin sponge with and without SEC adsorption. SEC had no effect on capillary formation. Bar, $2 \mathrm{~mm} . n=5$. (D) Inverted-phase contrast microscopy to show the effects of SEC on formation of the vascular-like structures in VECs on Matrigel, and its quantification indicated that the tube formation was not affected by SEC. Bar, $100 \mu \mathrm{M} . n=3$. Data are mean $\pm \mathrm{SEM} ;{ }^{*} p<0.05 ;{ }^{* *} p<0.01$. NS, no significance. 
Rho. Activation of Rho A and B small GTPases induced by transforming growth factor $\beta 1$ (TGF- $\beta 1$ ) increases LIM-kinase 2 (LIMK2) phosphorylation by ROCK. Activated LIMK2 then phosphorylates cofilin to promote actin reorganization [57]. We previously reported that ABO-induced inhibition of ANXA7 GTPase activity decreased the phosphorylation of GCA and TIA-1 [27, 58]. In the current study, SEC-activated ANXA7 GTPase increased the phosphorylation of ITGB4. Therefore, possible ANXA7 GTPase downstream kinase effectors may regulate the phosphorylation of target proteins. So far, the kinase effectors of ANXA7 GTPase have not been reported. Both Met and FGFR1 can promote ITGB4 Y1494 phosphorylation [15, 59]. SFKs phosphorylate major tyrosines located in the ITGB4 cytoplasm domain [2]. However, the receptor tyrosine kinases or cytoplasmic kinases are prone to bind to ITGB4 and form distinct complexes by recruiting other molecules [60-62]. Therefore, we presumed that activated ANXA7 associated with the related kinases to promote ITGB4 phosphorylation. ANXA7 indirectly associated with ITGB4 by capturing potential kinases, which acted as a linker to combine ITGB4 and ANXA7 to form a complex. The explicit mechanism needs to be explored.

Both SEC and ECPC can promote ITGB4 phosphorylation on Y1494, the ensuing ITGB4 nuclear translocation and the upregulation of apoptosis-related genes. The two small molecules function in a distinct action mechanism in different cell types. ECPC-induced ITGB4 phosphorylation was promoted by FGFR1 in vascular endothelium cells. SEC enhanced ITGB4 phosphorylation by binding to ANXA7 and activating ANXA7 GTPase in tumor cells. Whether a cross-link exists between the two mechanisms remains to be demonstrated. In addition, we extended our previous study by shedding light on the novel function of ITGB4 in the nucleus by binding to the $A T F 3$ promoter. The novel role of nuclear ITGB4 helps to explain the upregulation of apoptotic genes stimulated by ECPC and SEC.

In summary, we found that a small molecule, SEC, selectively promoted apoptosis in tumor cells with high expression of ITGB4. After enhancing ANXA7 GTPase activity, SEC triggers ITGB4 phosphorylation at Y1494, which induces ITGB4 nuclear translocation. Nuclear ITGB4 binds to $A T F 3$ promoter regions and promotes the transcription of downstream genes related to apoptosis (Figure 7). These results extend the scope of our study, emphasizing the roles of ITGB4 nuclear translocation in controlling tumor cell apoptosis and the explicit mechanism of pro-apoptosis signaling. The specificity of SEC for nuclear trafficking of ITGB4 and the apoptosispromoting effect support potential ITGB4 target drugs to combat ITGB4-related tumors.

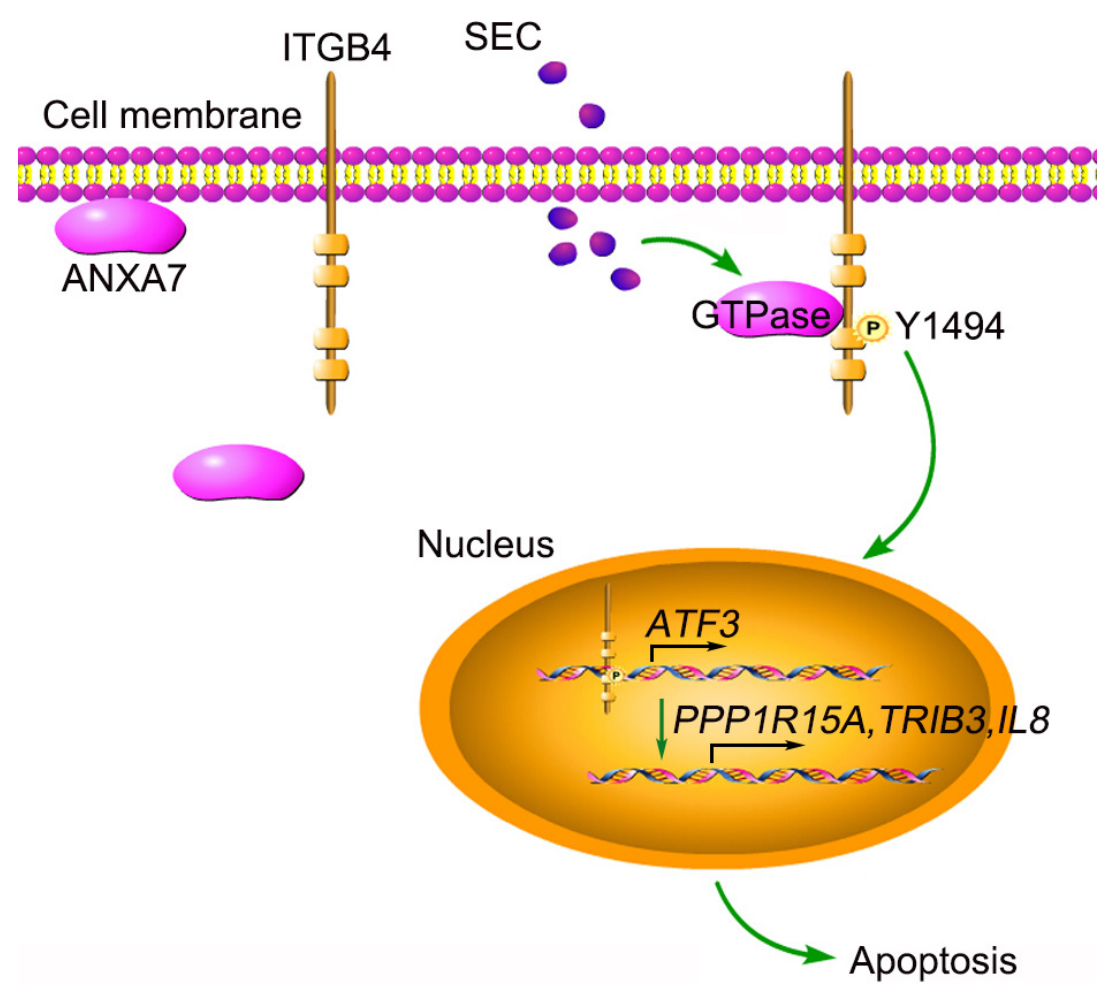

Figure 7: Schematic presentation of SEC-induced apoptosis by triggering ITGB4 nuclear translocation. SEC treatment increases ANXA7 GTPase activity and promotes the binding of ANXA7 to ITGB4, which contributes to the phosphorylation of ITGB4 Y1494. Subsequently, ITGB4 translocates to the nucleus. Nuclear ITGB4 binds to the ATF3 promoter region, activates $A T F 3$ transcription and promotes the expression of downstream apoptosis-related genes. 


\section{MATERIALS AND METHODS}

\section{Synthesis of the compound SEC}

(S)-2-((4-chlorophenoxy)methyl)oxirane was synthesized by the reaction of 4-chlorophenol with (S)-oxiran-2-ylmethyl 4-methylbenzenesulfonate. (S)-ethyl 1-(3-(4-chlorophenoxy)-2-hydroxypropyl)-3-(4methoxyphenyl)-1H-pyrazole-5-carboxylate (SEC) was obtained by the reaction of ethyl 3-(4-methoxyphenyl)1H-pyrazole-5-carboxylate with (S)-2-((4-chlorophenoxy) methyl)oxirane according to our previous report [63].

\section{Antibodies}

Antibodies for integrin $\beta 4$ (sc-9090), ANXA7 (sc-11389), $\alpha$-Tubulin (sc-5286), $\beta$-actin (sc-47778), GFP (sc-9996) and horseradish peroxidase-conjugated secondary antibodies were from Santa Cruz Biotechnology. Lamin A/C (2032) antibody was from CST. Antibody for phospho-Y-1494 integrin $\beta 4$ (ab29043) and mCherry (ab167453) were from Abcam. Secondary antibodies for immunofluorescence were goat anti-mouse IgG Alexa Fluor-488 (A11029) and goat anti-rabbit IgG Alexa Fluor-549 (A-11037; both Invitrogen).

\section{Cell culture}

HEK293 cells and MCF-7 cells were grown in Dulbecco's modified Eagle's medium (DMEM, Gibco, $12800-058$ ) with $10 \%$ fetal bovine serum (FBS; Hyclone, SV30087.02). L-02, PC3, A549 and HCT116 cells were cultured in RPMI Medium 1640 (Gibco, 3180-022) in the presence of 10\% FBS (Hyclone, SV30087.02). All cell lines were cultured in a humidified incubator at $37^{\circ} \mathrm{C}$ with $5 \% \mathrm{CO}_{2}$.

\section{Cell viability assay}

Treated cells were plated in 96-well plates, then precipitated for $1 \mathrm{~h}$ at $4^{\circ} \mathrm{C}$ with $100 \mu \mathrm{l} 10 \%$ trichloroacetic acid (Shenggong Biotech, Shanghai) and stained with $50 \mu \mathrm{l}$ sulforhodamine B (SRB; Sigma-Aldrich, USA). The optical density was read at $540 \mathrm{~nm}$ after reconstitution of the bound dye in $100 \mu \mathrm{l}$ of $10 \mathrm{mM}$ Trisbase (pH 10.5) by use of a Spec-traMAX 190 microplate spectrophotometer $($ GMI Co., USA). Cell viability $(\%)=(\mathrm{OD}$ of treated group/OD of control group) $\times 100$.

\section{Hoechst 33258 staining}

Live PC3, A549, HCT116 and MCF-7 cells were stained with Hoechst 33258 at $10 \mathrm{mg} / \mathrm{mL}$ in the medium for $15 \mathrm{~min}$ at $37^{\circ} \mathrm{C}$. Cells washed with PBS twice were observed under a fluorescence microscope (Nikon).
Apoptotic cells were identified by intense local staining of condensed DNA, with diffuse DNA staining in normal cells. At least 400 cells were counted for apoptotic cells.

\section{Cell morphology}

Morphologic changes of PC3 cells were observed by inverted phase-contrast microscopy (Eclipse TS-100; Nikon, Tokyo).

\section{Immunofluorescence assay}

Treated cells were fixed in $4 \%$ paraformaldehyde $(\mathrm{w} / \mathrm{v})$ for $30 \mathrm{~min}$ at room temperature, then incubated with normal goat serum (1:30) for 20 min and primary antibodies $(1: 100)$ overnight at $4^{\circ} \mathrm{C}$. Cells were washed with phosphate buffered saline (PBS) 3 times, then incubated with secondary antibodies $(1: 200)$ for $1 \mathrm{~h}$ at $37^{\circ} \mathrm{C}$. Fluorescence was detected by laser scanning confocal microscopy (Leica, Wetzlar, Germany).

\section{RT-PCR and quantitative real-time PCR}

Extraction of total RNA involved use of Trizol reagent (Invitrogen, USA). cDNA was synthesized with $2 \mu \mathrm{g}$ RNA by use of M-MLV reverse transcriptase (Promega, USA). For RT-PCR, mastermix (MegaMix, Cambio) was used. For quantitative real-time PCR, the ABI7000 system with SYBR Green PCR master Mix (Takara, DRR041A) was used. The expression of $\beta$-actin was used to normalize with a melting curve for each reaction. Primers for PCR were for ITGB4, sense 5'-TCTGGCCTTCAATGTCGTCT-3', and anti-sense 5'-GGGATGATGGGGATGGACAT-3'; and $\beta$-actin, sense 5'-GAAGTGTGACGTGGACATCC-3', and anti-sense 5'-CCGATCCACACGGAGTACTT-3'. Primers for microarray confirmation are in Supplementary Table 1.

\section{Chromatin immunoprecipitation (ChIP)}

ChIP was performed with ChIP kits (Millipore, 17-10086) according to the user manual. Briefly, PC3 cells were fixed in $1 \%$ formaldehyde incubated at room temperature for $10 \mathrm{~min}$. Approximately $10^{7}$ cells were lysed in $0.5 \mathrm{ml}$ lysis buffer. Isolated chromatin was sheared by sonication to a mean length of about $500 \mathrm{bp}$. An amount of $50 \mu \mathrm{l}$ of chromatin was immunoprecipitated with $6 \mu \mathrm{g}$ ITGB4 antibody and $1 \mu \mathrm{g}$ normal rabbit IgG for negative control overnight at $4{ }^{\circ} \mathrm{C}$ with rotation; $20 \mu$ fully resuspended protein $\mathrm{A} / \mathrm{G}$ magnetic beads were added. The Protein A/G bead-antibody/chromatin complexes were washed and eluted. Then the cross-links of protein/DNA complexes were reversed to free DNA. Finally, $50 \mu \mathrm{DNA}$ solution was obtained for further analysis. Eight primers for PCR are in Supplementary Table 2. 


\section{Terminal deoxynucleotidyl transferase-mediated dUTP nick-end labeling (TUNEL)}

The TUNEL assay was performed as described [64]. The DeadEndTM Fluorometric TUNEL System (Promega, USA) was used to detect DNA fragmentation of treated cells and tumor tissues. Apoptosis was assessed by laser scanning confocal microscopy (Leica, Wetzlar, Germany).

\section{In vitro ANXA7 activity assay}

The coding region of human wide type ANXA7 and ANXA7-mt1 (T275A) and -mt2 (T286A) mutants were subcloned into the mCherry-N1 expression vector with a $6 *$ His tag. When the density of HEK293 plated onto $10-\mathrm{cm}$ dishes reached $70 \%$ to $80 \%$ confluence, cells were transfected with the indicated expression vector. At $24 \mathrm{~h}$ after transection, total proteins were harvested, and expressed recombinant ANXA7 was extracted and purified by column chromatography by use of the His GraviTrap Ni-NTA protein purification assay kit. Purified ANXA7 was incubated at $37^{\circ} \mathrm{C}$ with or without SEC for indicated concentrations and times. The GTPase activity of ANXA7 was measured with use of the ATPase/GTPase Activity Assay Kit (MAK113, Sigma, USA).

\section{Western blot analysis}

Western blot assay was conducted as previously described [65]. Equal amounts of protein were applied to $9 \%$ SDS-polyacrylamide gel for ITGB4 and 12\% SDS-polyacrylamide gel for other proteins. Proteins in gels were electroblotted onto poly-vinylidene difluoride membranes and blocked at room temperature for $1 \mathrm{~h}$, then probed with primary antibodies overnight at $4^{\circ} \mathrm{C}$. After 3 washes in PBST, membranes were incubated with peroxidase-conjugated secondary antibodies for $1 \mathrm{~h}$ at room temperature, and proteins were detected by use of an enhanced chemiluminesence detection kit (Thermo Fisher, 34080). The relative quantity of protein levels was analyzed by use of ImageJ and normalized to loading controls.

\section{Immunoprecipitation (IP)}

PC3 cells were lysed in IP buffer (Beyotime, P0013). The lysates were pre-cleared with protein $A / G$ agarose beads (Beyotime, P2012) for $1 \mathrm{~h}$ at $4^{\circ} \mathrm{C}$. After centrifugation, the supernatant was collected and incubated with specific antibodies or normal corresponding $\operatorname{IgG}$, then with protein $\mathrm{A} / \mathrm{G}$ beads overnight at $4^{\circ} \mathrm{C}$. The beads were rinsed with IP buffer 3 times and eluted with $2 \times$ SDS loading buffer. The immunoprecipitated proteins were detected by western blot assay.

\section{Plasmids and overexpression}

mCherry-labelled ANXA7 wild-type (mCherryANXA7-wt) and mCherry-ANXA7-mt1 (T275A), -mt2 (T286A) and $-\mathrm{mt} 3$ (T286D) mutants were constructed as described [27]. The coding regions of ITGB4 and Y1494A mutant were subcloned into the pEGFP-C2 expression vector to produce the pEGFPC2-ITGB4 and Y1494A mutant constructs. PC3 or HEK293 cells at $70 \%$ to $80 \%$ confluence were transfected with the expression vectors for $24 \mathrm{~h}$ by use of Lipofectamine 2000 (Invitrogen, 11668-019) according to the manufacturer's instructions. Then cells were harvested and analyzed by western blot or fluorescence assay.

\section{RNA interference}

Specific siRNA against ANXA7 was designed and custom-synthesized by Invitrogen; ITGB4 siRNA (sc-35678) and scramble RNA (sc-37007) were obtained from Santa Cruz Biotechnology. PC3 cells at $70 \%$ to $80 \%$ confluence were transfected with $40 \mathrm{nM}$ siRNA against ANXA7, ITGB4 and scramble siRNA with Lipofectamine 2000 (Invitrogen, 11668-019) according to the manufacturer's instructions. Then cells were harvested and analyzed by western blot.

\section{Capillary tube formation assay}

The capillary-like tube formation assay was performed as previously described [66]. Matrigel was added to 24-well plates and allowed to polymerize for $1 \mathrm{~h}$ at $37^{\circ} \mathrm{C}$. Human umbilical vein endothelial cells (HUVECs) were seeded on 24-well plates at 4-5 $\times 10^{4}$ cells/well in M199 medium, treated with or without SEC in the presence FGF-2 and serum, then incubated at $37^{\circ} \mathrm{C}$ for $24 \mathrm{~h}$. Tube formation was observed under an invertedphase contrast microscope (Nikon, Tokyo). The degree of tube formation was quantified by measuring the number of tubes in random fields from each well using the ImageJ.

\section{In vivo tumor assay of chick embryo chorioallantoic membrane (CAM)}

Fertilized chicken eggs were incubated at $37.8^{\circ} \mathrm{C}$ with $60 \%$ relative humidity. On embryonic day 10 , a silicone ring with a 5-mm inner diameter was placed on the CAM, and 6 million A549 cells in $20 \mu \mathrm{l}$ of medium were seeded into this silicone ring. Four separate groups of 5 eggs each were divided. On day 2, SEC was deposited at $0.2 \mu \mathrm{mol}$ (low dose) or $0.5 \mu \mathrm{mol}$ (high dose) per egg every 2 days. $5 \mathrm{FU}(0.5 \mu \mathrm{mol})$ treatment was a positive control. At 6 days after SEC and 5FU treatment, the CAM and tumor were sampled. Tumor size-matching was based on 
tumor volume calculation: length $\times$ width $\times$ width $\times 0.5$. Tumor tissues were fixed in $4 \%$ paraformaldehyde, snapfrozen in optimal cutting temperature embedding medium (Tissue-Tek, 4583), and cut into $9-\mu \mathrm{m}$ cryosections.

\section{Angiogenesis assay of CAM in vivo}

Fertilized chicken eggs were incubated at $37.8^{\circ} \mathrm{C}$ with $60 \%$ relative humidity. On embryonic day 10 , SEC $(0.2 \mu \mathrm{mol} / 20 \mu \mathrm{l}$ and $0.5 \mu \mathrm{mol} / 20 \mu \mathrm{l})$ soaked in the gelatin sponge was applied to the CAM. CAMs were treated with SEC and DMSO as the vehicle control. Eggs were incubated for a further 6 days. At the end of the incubation, the CAM zones around the gelatin sponge were photographed and analyzed by using the Image-Pro Plus.

\section{Statistical analysis}

Data are presented as mean \pm SEM and were analyzed by one-way ANOVA with SPSS v11.5 (SPSS Inc., Chicago, IL). $P<0.05$ was considered statistically significant. Mean values were derived from at least 3 independent experiments.

\section{ACKNOWLEDGMENTS AND FUNDING}

This work was supported by the National Natural Science Foundation of China (nos. 91313303, 31570834, 31270877, 20972088, 31070735) and the Key Technology Special Project of Shandong Province (nos. 2015ZDJS04001 and 2015ZDJS04003).

\section{CONFLICTS OF INTEREST}

The authors declare no conflicts of interest.

\section{REFERENCES}

1. Soung YH, Gil HJ, Clifford JL, Chung J. Role of $\alpha 6 \beta 4$ integrin in cell motility, invasion and metastasis of mammary tumors. Curr Protein Pept Sci. 2011; 12:23-29.

2. Giancotti FG. Targeting integrin beta4 for cancer and antiangiogenic therapy. Trends Pharmacol Sci. 2007; 28:506-511.

3. Lipscomb EA, Mercurio AM. Mobilization and activation of a signaling competent alpha6beta4integrin underlies its contribution to carcinoma progression. Cancer Metastasis Rev. 2005; 24:413-423.

4. Kashyap T, Germain E, Roche M, Lyle S, Rabinovitz I. Role of $\beta 4$ integrin phosphorylation in human invasive squamous cell carcinoma: regulation of hemidesmosome stability modulates cell migration. Lab Invest. 2011; 91:1414-1426.

5. Gagnoux-Palacios L, Dans M, van't Hof W, Mariotti A, Pepe A, Meneguzzi G, Resh MD , Giancotti FG. Compartmentalization of integrin alpha6beta4 signaling in lipid rafts. J Cell Biol. 2003; 162:1189-1196.
6. Ngora H, Galli UM, Miyazaki K, Zoller M. Membranebound and exosomal metastasis-associated $\mathrm{C} 4$.4A promotes migration by associating with the alpha(6)beta(4) integrin and MT1-MMP. Neoplasia. 2012; 14:95-107.

7. Thundimadathil J. Cancer treatment using peptides: current therapies and future prospects. J Amino Acids. 2012; 2012:967347.

8. Nistico P, Di Modugno F, Spada S, Bissell MJ. $\beta 1$ and $\beta 4$ integrins: from breast development to clinical practice. Breast Cancer Res. 2014; 16:459.

9. Feng C, Ye C, Liu X, Ma H, Li M. Beta4 integrin is involved in statin-induced endothelial cell death. Biochem Biophys Res Commun. 2004; 323:858-864.

10. Miao JY, Araki S, Kaji K, Hayashi H. Integrin beta4 is involved in apoptotic signal transduction in endothelial cells. Biochem Biophys Res Commun. 1997; 233:182-186.

11. Zhao J, Miao J, Zhao B, Zhang S. Upregulating of Fas, integrin beta 4 and P53 and depressing of PC-PLC activity and ROS level in VEC apoptosis by safrole oxide. FEBS Lett. 2005; 579:5809-5813.

12. Fan C, Su H, Zhao J, Zhao B, Zhang S, Miao J. A novel copper complex of salicylaldehyde pyrazole hydrazone induces apoptosis through up-regulating integrin beta4 in H322 lung carcinoma cells. Eur J Med Chem. 2010; 45:1438-1446.

13. Zhang L, Zhu X, Zhao B, Zhao J, Zhang Y, Zhang S, Miao J. A novel isochroman derivative inhibited apoptosis in vascular endothelial cells through depressing the levels of integrin beta4, p53 and ROS. Vascul Pharmacol. 2008; 48:63-69.

14. Dong Z, Wang L, Xu J, Li Y, Zhang Y, Zhang S, Miao J. Promotion of autophagy and inhibition of apoptosis by low concentrations of cadmium in vascular endothelial cells. Toxicol In Vitro. 2009; 23:105-110.

15. Ge D, Kong X, Liu W, Zhao J, Su L, Zhang S, Zhang Y, Zhao B , Miao J. Phosphorylation and nuclear translocation of integrin $\beta 4$ induced by a chemical small molecule contribute to apoptosis in vascular endothelial cells. Apoptosis. 2013; 18:1120-1131.

16. Wilhelmsen K, Litjens SH, Kuikman I, Margadant C, van Rheenen J , Sonnenberg A. Serine phosphorylation of the integrin beta4 subunit is necessary for epidermal growth factor receptor induced hemidesmosome disruption. Mol Biol Cell. 2007; 18:3512-3522.

17. Rabinovitz I, Tsomo L, Mercurio AM. Protein kinase C-alpha phosphorylation of specific serines in the connecting segment of the beta 4 integrin regulates the dynamics of type II hemidesmosomes. Mol Cell Biol. 2004; 24:4351-4360.

18. Dans M, Gagnoux-Palacios L, Blaikie P, Klein S, Mariotti A, Giancotti FG. Tyrosine phosphorylation of the beta 4 integrin cytoplasmic domain mediates She signaling to extracellular signal-regulated kinase and antagonizes formation of hemidesmosomes. J Biol Chem. 2001; 276:1494-1502. 
19. Dutta U, Shaw LM. A key tyrosine (Y1494) in the beta4 integrin regulates multiple signaling pathways important for tumor development and progression. Cancer Res. 2008; 68:8779-8787.

20. Shaw LM. Identification of insulin receptor substrate 1 (IRS-1) and IRS-2 as signaling intermediates in the alpha6beta4 integrin-dependent activation of phosphoinositide 3-OH kinase and promotion of invasion. Mol Cell Biol. 2001; 21:5082-5093.

21. Gerke V, Moss SE. Annexins: from structure to function. Physiol Rev. 2002; 82:331-371.

22. Selbert S, Fischer P, Pongratz D, Stewart M, Noegel AA. Expression and localization of annexin VII (synexin) in muscle cells. J Cell Sci. 1995; 108:85-95.

23. Clemen CS, Herr C, Lie AA, Noegel AA, Schroder R. Annexin VII: an astroglial protein exhibiting a $\mathrm{Ca} 2+$ -dependent subcellular distribution. Neuroreport. 2001; 12:1139-1144.

24. Gerelsaikhan T, Vasa PK, Chander A. Annexin A7 and SNAP23 interactions in alveolar type II cells and in vitro: a role for $\mathrm{Ca}(2+)$ and PKC. Biochim Biophys Acta. 2012; 1823:1796-1806.

25. Srivastava M, Bubendorf L, Srikantan V, Fossom L, Nolan L, Glasman M, Leighton X, Fehrle W, Pittaluga S, Raffeld M, Koivisto P, Willi N, Gasser TC, et al. ANX7, a candidate tumor suppressor gene for prostate cancer. Proc Natl Acad Sci U S A. 2001; 98:4575-4580.

26. Srivastava M, Montagna C, Leighton X, Glasman M, Naga S, Eidelman O, Ried T, Pollard HB. Haploinsufficiency of Anx7 tumor suppressor gene and consequent genomic instability promotes tumorigenesis in the Anx7(+/-) mouse. Proc Natl Acad Sci U S A. 2003; 100:14287-14292.

27. Li H, Liu N, Wang S, Wang L, Zhao J, Su L, Zhang Y, Zhang S, Xu Z, Zhao B , Miao J. Identification of a small molecule targeting annexin A7. Biochim Biophys Acta. 2013; 1833:2092-2099.

28. Li H, Huang S, Wang S, Wang L, Qi L, Zhang Y, Zhang S, Zhao B , Miao J. Relationship between annexin A7 and integrin $\beta 4$ in autophagy. Int J Biochem Cell Biol. 2013; 45:2605-2611.

29. Jiang HY, Wek SA, McGrath BC, Lu D, Hai T, Harding HP, Wang X, Ron D, Cavener DR, Wek RC. Activating transcription factor 3 is integral to the eukaryotic initiation factor 2 kinase stress response. Mol Cell Biol. 2004; 24:1365-1377.

30. Aung HH, Lame MW, Gohil K, An CI, Wilson DW, Rutledge JC. Induction of ATF3 gene network by triglyceride-rich lipoprotein lipolysis products increases vascular apoptosis and inflammation. Arterioscler Thromb Vasc Biol. 2013; 33:2088-2096.

31. Chhabra R, Dubey R, Saini N. Gene expression profiling indicate role of ER stress in miR-23a 27a 24-2 cluster induced apoptosis in HEK293T cells. RNA Biol. 2011; 8:648-664.
32. Chan JY, Cooney GJ, Biden TJ, Laybutt DR. Differential regulation of adaptive and apoptotic unfolded protein response signalling by cytokine-induced nitric oxide production in mouse pancreatic beta cells. Diabetologia. 2011; 54:1766-1776.

33. Yuan YJ, Xu K, Wu W, Luo Q, Yu JL. Application of the chick embryo chorioallantoic membrane in neurosurgery disease. Int J Med Sci. 2014; 11:1275-1281.

34. Lokman NA, Elder AS, Ricciardelli C, Oehler MK. Chick Chorioallantoic Membrane (CAM) Assay as an in Vivo Model to Study the Effect of Newly Identified Molecules on Ovarian Cancer Invasion and Metastasis. Int J Mol Sci. 2012; 13:9959-9970.

35. Ribatti D. Chicken chorioallantoic membrane angiogenesis model. Methods Mol Biol. 2012; 843:47-57.

36. Yoshioka T, Otero J, Chen Y, Kim YM, Koutcher JA, Satagopan J, Reuter V, Carver B, de Stanchina E, Enomoto K, Greenberg NM, Scardino PT, Scher HI, et al. $\beta 4$ Integrin signaling induces expansion of prostate tumor progenitors. J Clin Invest. 2013; 123:682-699.

37. Carmeliet P, Jain RK. Principles and mechanisms of vessel normalization for cancer and other angiogenic diseases. Nat Rev Drug Discov. 2011; 10:417-427.

38. Al-Zoughbi W, Huang J, Paramasivan GS, Till H, Pichler M, Guertl-Lackner B , Hoefler G. Tumor macroenvironment and metabolism. Semin Oncol. 2014; 41:281-295.

39. Pu H, Wang X, Su L, Ma C, Zhang Y, Zhang L, Chen X, Li X, Wang H, Liu X, Zhang J. Heroin activates ATF3 and CytC via c-Jun $\mathrm{N}$-terminal kinase pathways to mediate neuronal apoptosis. Med Sci Monit Basic Res. 2015; 21:53-62.

40. Kim KJ, Lee J, Park Y and Lee SH. ATF3 Mediates Anti-Cancer Activity of Trans-10, cis-12-Conjugated Linoleic Acid in Human Colon Cancer Cells. Biomol Ther. 2015; 23:134-140.

41. Crawford RR, Prescott ET, Sylvester CF, Higdon AN, Shan J, Kilberg MS , Mungrue IN. Human CHAC1 Protein Degrades Glutathione, and mRNA Induction Is Regulated by the Transcription Factors ATF4 and ATF3 and a Bipartite ATF/CRE Regulatory Element. J Biol Chem. 2015; 290:15878-15891.

42. Wu H, Wei L, Fan F, Ji S, Zhang S, Geng J, Hong L, Fan X, Chen Q, Tian J, Jiang M, Sun X, Jin C, et al. Integration of Hippo signalling and the unfolded protein response to restrain liver overgrowth and tumorigenesis. Nat Commun. 2015; 6:6239.

43. Lee JI, Dominy JE, Jr., Sikalidis AK, Hirschberger LL, Wang W , Stipanuk MH. HepG2/C3A cells respond to cysteine deprivation by induction of the amino acid deprivation/integrated stress response pathway. Physiol Genomics. 2008; 33:218-229.

44. Ohoka N, Yoshii S, Hattori T, Onozaki K and Hayashi H. TRB3, a novel ER stress-inducible gene, is induced via ATF4-CHOP pathway and is involved in cell death. EMBO J. 2005; 24:1243-1255. 
45. Lo HW, Ali-Seyed M, Wu Y, Bartholomeusz G, Hsu SC, Hung MC. Nuclear-cytoplasmic transport of EGFR involves receptor endocytosis, importin beta1 and CRM1. J Cell Biochem. 2006; 98:1570-1583.

46. Wang YN, Lee HH, Lee HJ, Du Y, Yamaguchi H, Hung MC. Membrane-bound trafficking regulates nuclear transport of integral epidermal growth factor receptor (EGFR) and ErbB-2. J Biol Chem. 2012; 287:16869-16879.

47. Brand TM, Iida M, Luthar N, Starr MM, Huppert EJ, Wheeler DL. Nuclear EGFR as a molecular target in cancer. Radiother Oncol. 2013; 108:370-377.

48. Provenzano MJ, Minner SA, Zander K, Clark JJ, Kane CJ, Green SH, Hansen MR. p75(NTR) expression and nuclear localization of p75(NTR) intracellular domain in spiral ganglion Schwann cells following deafness correlate with cell proliferation. Mol Cell Neurosci. 2011; 47:306-315.

49. Hsu SC, Hung MC. Characterization of a novel tripartite nuclear localization sequence in the EGFR family. J Biol Chem. 2007; 282:10432-10440.

50. Giri DK, Ali-Seyed M, Li LY, Lee DF, Ling $P$, Bartholomeusz G, Wang SC , Hung MC. Endosomal transport of ErbB-2: mechanism for nuclear entry of the cell surface receptor. Mol Cell Biol. 2005; 25:11005-11018.

51. Caohuy H, Pollard HB. Protein kinase $\mathrm{C}$ and guanosine triphosphate combine to potentiate calcium-dependent membrane fusion driven by annexin 7. J Biol Chem. 2002; 277:25217-25225.

52. Salzer U, Hinterdorfer P, Hunger U, Borken C, Prohaska R. $\mathrm{Ca}(++)$-dependent vesicle release from erythrocytes involves stomatin-specific lipid rafts, synexin (annexin VII), and sorcin. Blood. 2002; 99:2569-2577.

53. Seltmann K, Cheng F, Wiche G, Eriksson JE, Magin TM. Keratins Stabilize Hemidesmosomes through Regulation of $\beta 4$ Integrin Turnover. J Invest Dermatol. 2015; 135:1609-1620.

54. Iida M, Brand TM, Campbell DA, Li C, Wheeler DL. Yes and Lyn play a role in nuclear translocation of the epidermal growth factor receptor. Oncogene. 2013; 32:759-767.

55. Huang WC, Chen YJ, Li LY, Wei YL, Hsu SC, Tsai SL, Chiu PC, Huang WP, Wang YN, Chen $\mathrm{CH}$, Chang WC, Chang WC, Chen AJ, et al. Nuclear translocation of epidermal growth factor receptor by Akt-dependent phosphorylation enhances breast cancer-resistant protein expression in gefitinib-resistant cells. J Biol Chem. 2011; 286:20558-20568.

56. Pasapera AM, Plotnikov SV, Fischer RS, Case LB, Egelhoff TT, Waterman CM. Rac1-dependent phosphorylation and focal adhesion recruitment of myosin
IIA regulates migration and mechanosensing. Curr Biol. 2015; 25:175-186.

57. Vardouli L, Moustakas A and Stournaras C. LIM-kinase 2 and cofilin phosphorylation mediate actin cytoskeleton reorganization induced by transforming growth factor-beta. J Biol Chem. 2005; 280:11448-11457.

58. Huang S, Liu N, Li H, Zhao J, Su L, Zhang Y, Zhang S, Zhao B, Miao J. TIA1 interacts with annexin A7 in regulating vascular endothelial cell autophagy. Int $\mathrm{J}$ Biochem Cell Biol. 2014; 57:115-122.

59. Bertotti A, Comoglio PM, Trusolino L. Beta4 integrin activates a Shp2-Src signaling pathway that sustains HGFinduced anchorage-independent growth. J Cell Biol. 2006; 175:993-1003.

60. Wang H, Jin H, Rapraeger AC. Syndecan-1 and Syndecan-4 Capture Epidermal Growth Factor Receptor Family Members and the $\alpha 3 \beta 1$ Integrin Via Binding Sites in Their Ectodomains: NOVEL SYNSTATINS PREVENT KINASE CAPTURE AND INHIBIT alpha6beta4-INTEGRINDEPENDENT EPITHELIAL CELL MOTILITY. J Biol Chem. 2015; 290:26103-26113.

61. Wang H, Jin H, Beauvais DM, Rapraeger AC. Cytoplasmic domain interactions of syndecan-1 and syndecan-4 with a6ß4 integrin mediate human epidermal growth factor receptor (HER1 and HER2)-dependent motility and survival. J Biol Chem. 2014; 289:30318-30332.

62. Ephstein Y, Singleton PA, Chen W, Wang L, Salgia R, Kanteti P, Dudek SM, Garcia JG, Jacobson JR. Critical role of S1PR1 and integrin $\beta 4$ in HGF/c-Met-mediated increases in vascular integrity. J Biol Chem. 2013; 288:2191-2200.

63. Wei F, Zhao BX, Huang B, Zhang L, Sun CH, Dong WL, Shin DS, Miao JY. Design, synthesis, and preliminary biological evaluation of novel ethyl 1-(2'-hydroxy-3'aroxypropyl)-3-aryl-1H-pyrazole-5-carboxylate. Bioorg Med Chem Lett. 2006; 16:6342-6347.

64. Gavrieli Y, Sherman Y, Ben-Sasson SA. Identification of programmed cell death in situ via specific labeling of nuclear DNA fragmentation. J Cell Biol. 1992; 119:493-501.

65. Du AY, Zhao BX, Yin DL, Zhang SL, Miao JY. Discovery of a novel small molecule, 1-ethoxy-3- (3, 4-methylenedioxyphenyl)-2-propanol, that induces apoptosis in A549 human lung cancer cells. Bioorg Med Chem. 2005; 13:4176-4183.

66. Lawley TJ, Kubota Y. Induction of morphologic differentiation of endothelial cells in culture. J Invest Dermatol. 1989; 93:59S-61S. 